\title{
A study of athletic abilities in idiopathic scoliosis patients with brace therapy
}

\author{
Akiko Misawa*, Yoichi Shimada, Naohisa Miyakoshi, Michio Hongo, \\ Yuji Kasukawa and Shigeru Ando
}

\author{
Address: Rehabilitation Division, Akita University Hospital, Japan
}

* Corresponding author

\author{
from $5^{\text {th }}$ International Conference on Conservative Management of Spinal Deformities \\ Athens, Greece. 3-5 April 2008 \\ Published: 15 January 2009 \\ Scoliosis 2009, 4(SuppI I):O40 doi:I0.I I86/I748-7|6I-4-SI-O40
}

This abstract is available from: http://www.scoliosisjournal.com/content/4/SI/O40

(C) 2009 Misawa et al; licensee BioMed Central Ltd.

\section{Background}

Brace therapy for scoliosis patients may reduce the flexibility of the spine due to the correction of the trunk during the patient's high growth period. However, the influence of brace therapy on athletic ability is still unknown.

\section{Goal}

The purpose of this study is to investigate athletic abilities in scoliosis patients during partial brace therapy.

\section{Methods}

Ninety-six idiopathic scoliosis patients treated with brace therapy for more than one year were investigated. The average age was 14.3 years. The follow-up period averaged 4.5 years. There were 77 patients with an Osaka Medical College brace, 15 with a Boston brace, and 4 with other braces. All patients applied the brace only at night.

Subjective flexibility of the spine after brace therapy was evaluated. Athletic abilities, including running short and long distance, along with athletic club activities in school were also investigated.

\section{Results}

The subjective flexibility of the spine was reduced severely in $8 \%$ of the patients, and slightly in $42 \%$ of the patients. Short distance running ability was higher than "Normal" in $60 \%$ of the patients and it was also higher in $52 \%$ of the patients for long distance running before brace therapy. After brace therapy, athletic ability was unchanged in
$91.7 \%$ of the patients. Thirty-eight percents of the patients belonged to a sports club in school. While thirteen percent of patients complained of a reduction in athletic ability during brace therapy.

\section{Conclusion}

We conclude that the influence of partial brace therapy on athletic abilities in idiopathic scoliosis patients is fairly low. 